\title{
Keratinolysis of chicken feather and human hair by nondermatophytic keratinophilic fungi isolated from soil
}

\author{
Jitendra Kumar* \\ Department of Botany, Dolphin PG College of Science and Agriculture, Chunni Kalan \\ Fatehgarh Sahib (Punjab), India \\ Ranjana Yadav \\ Indian Plywood Industries Research and Training Institute Centre, Mohali (Punjab), India \\ ${ }^{*}$ Corresponding author. Email: jeetmicro@gmail.com
}

\section{How to Cite}

Kumar J. and Yadav R. (2020). Keratinolysis of chicken feather and human hair by nondermatophytic keratinophilic fungi isolated from soil. Journal of Applied and Natural Science, 12(4): 568 - 574. https://doi.org/10.31018/jans.v12i4.2398

\section{Article Info}

https://doi.org/10.31018/ jans.v12i4.2398

Received: October 15, 2020

Revised: November 23, 2020

Accepted: November 25, 2020

\begin{abstract}
Development in food industry increases consumption of chicken by people and it is estimated that tons of poultry feathers are produced by poultry farms. Hairs are other forms of keratinous waste which is generated in huge amounts by leather industries and parlours worldwide. Chicken feathers and hairs are waste contains high-quality protein, hard to degraded. Eleven nondermatophytic keratinophilic fungi were isolated from soil by hair baiting method and were used to deteriorate hairs and feathers. Pictographic authentication showed that the microbial incidence started with surface colonization of keratinous substrate, mechanical interference of substrate by penetrating hyphae and development of broad perforating organs. Fourier Transform Infrared Spectroscopy (FTIR) analysis of degraded and undegraded hair and the feather was made. In the sulphoxide region at 1073 , the band corresponding to S-O was observed with low intensity and poorly visible in control feathers, while in degraded feather intensity of the band was high in case of Chrysosporium indicum and Chrysosporium tropicum. In Hairs, S-O band was more intense in $C$ indicum as compared to $C$. tropicum while it was absent in undegraded human hair. The present work observed keratin degradation activity on human hair and chicken feather by FTIR spectra which are useful in the study of structure and mechanism of keratinolysis. Keratinous waste degradation has great potential to convert them into various byproducts such as enzymes, amino acids, biofertilizer and animal feed.
\end{abstract}

Keywords: FTIR analysis, Hair degradation, Feather degradation, Keratin degradation, Keratinophilic fungi

\section{INTRODUCTION}

The utilization of chicken by people is rising and it is estimated that worldwide 24 billion chickens are killed annually and 8.5 billion tons poultry feathers are produced, while India contributed about 350 million tons annually (Peng et al., 2019). Chicken feather is a waste of poultry industries, high-quality protein supplement owing to their crude protein content of more than $85 \%$ (Sahoo et al., 2012) while hairs are produced by leather industry and parlours. Keratinophilic fungi were isolated from various habitats as poultry farm soil (Deshmukh 1999, Kaul and Sumbali 1999), public parks (Ramesh and Hilda 1999) and glaciers (Caretta and Pointelli 2004). Hubalek (2000) carried out a detailed study of these fungi on birds and free-living animals. These fungi were isolated from soil by several researchers (Deshmukh and Verekar 2006, Deshmukh et al., 2010, Sharma 2016, Bairwa and Sharma 2020). Dermatophyte and non-dermatophytic fungi can inhabit in and invade the keratin of hair, nail, skin and feath- ers. For four decades the newly discovered keratinophilic fungi have been known as causes of skin infections in humans and animals (Kwon-Chung and Bennett 1992, Kane et al., 1997). Nondermatophytic fungi are capable of degrading keratin and producing keratinase (Nigam and Kushwaha 1992, Kumar and Kushwaha 2014). Studies of keratin deterioration by fungi are limited to very few in number (Kunert 1972, Safranek and Goos 1982, Nigam and Kushwaha 1990). Very few records are available to demonstrate the keratin colonizing capacity by dermatophytes and non dermatophytic fungi. However, keratinolytic activity of these fungi has been studied by many researchers (Filipello 1986, Wawrzkiewicz et al., (1991), Kumar and Kushwaha 2014, Kumar et al., (2015), Bohacz et al., (2020). Keratin degradation is attracting biotechnological attention since it might provide a substitute way of waste management as well as the production of valuable products (Brandeli and Riffel 2006, Pasupuleti et al., 2010). Feathers were degraded in soil 
and used as fertilizer for growth enhancement of plants (Kumar et al., 2020, Kumari and Kumar 2020). Nondermatophytic fungi occur in nature as soil-dwelling saprophytes and may be pathogenic. Considerable attention has been given to well-known pathogens while non dermatophytic fast-growing filamentous fungi have less been studied. The aim of the present study is to demonstrate the chicken feather and human hair deterioration activity of some non dermatophytic fungi using FTIR analysis. These fungi could be natural scavenging tools for keratinous waste management.

\section{MATERIALS AND METHODS}

Isolation and screening: The non dermatophytic fungi were isolated from urban waste habitats by the hair baiting method of Benedek (1962). Human hair obtained from a parlour shop while chicken feathers obtained from a butcher shop were washed in water and dried in air. Human hair and chicken feathers were cut into $1 \mathrm{~cm}$ length autoclaved at $15 \mathrm{lbs}$ pressure for 20 minutes. The inoculums were prepared in a homo- geneous suspension. Sterilized baits were placed in petri plates to $20 \mathrm{ml}$ of distilled water, $5 \mathrm{ml}$ fungal inoculum and $3 \mathrm{ml}$ of $10 \%$ yeast extract were added. The inoculated plates were incubated at $28 \pm 2{ }^{\circ} \mathrm{C}$ in the dark for 10 days. The control contained $25 \mathrm{ml}$ of sterilized distilled water and fungal inoculum. All the experiments were carried out in triplicate.

Fourier transform infrared spectroscopy (FTIR) analysis: Degradation chicken feathers and human hairs by fungal isolates were performed by FTIR analysis. FTIR spectra were recorded by using the Perkin Elmer spectrum EX, FTIR having a resolution of $\mathrm{cm}^{-1}$ and scan range $4000 \mathrm{~cm}^{-1}$ to $250 \mathrm{~cm}^{-1}$ in the SAIF Laboratory PU \& CIF LPU.

\section{RESULTS AND DISCUSSION}

Hyphal entrance in human hair may lead to tunnels which later on proceeded in length and width and consequently wide fissures developed and were the cause of mechanical disruption of hair (Fig. 1). These were thin, filamentous and narrow cone-shaped hyphae. Linear strands of Malbranchea sp. were seen. This

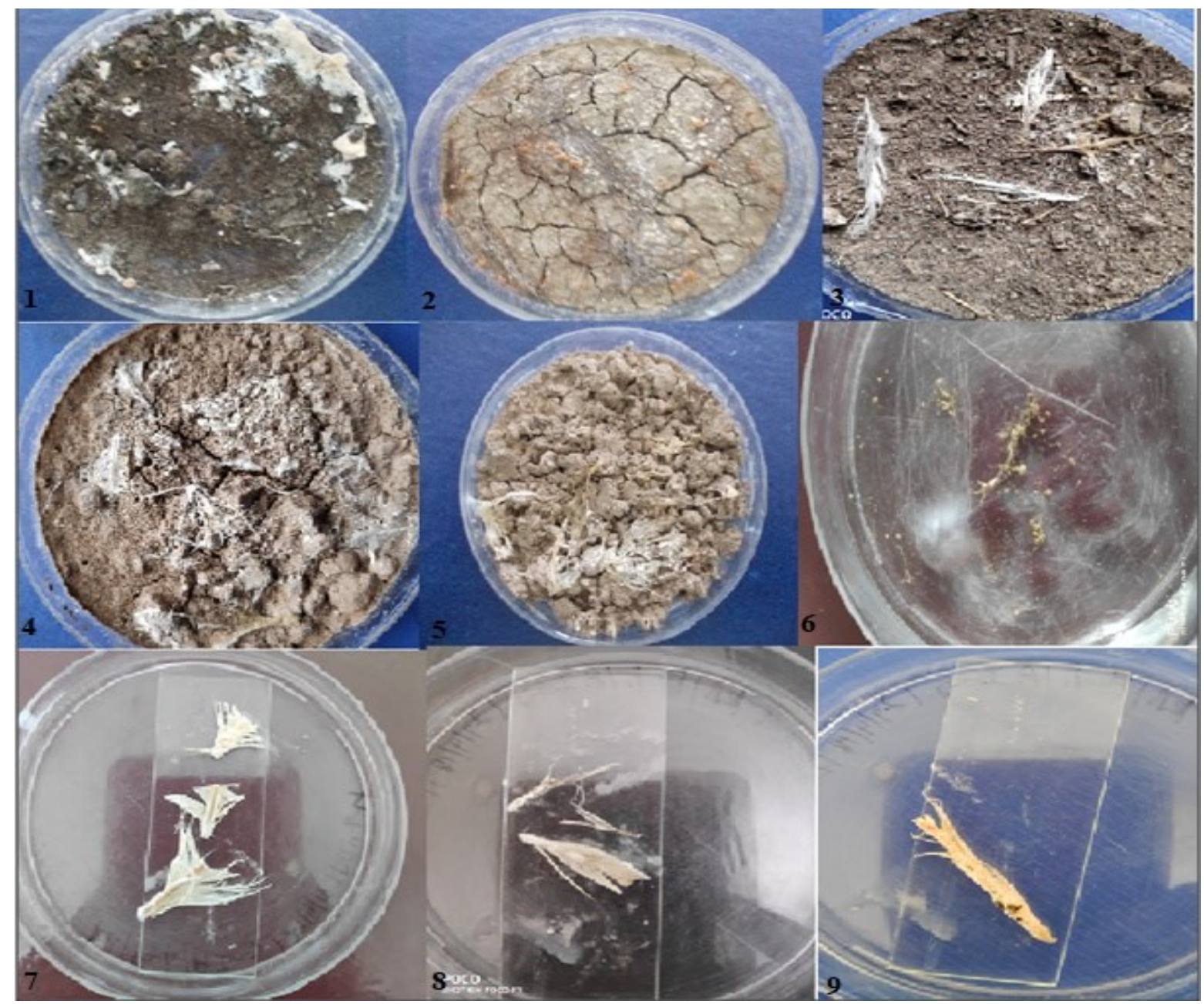

Figs. 1-9: 1. Growth of keratinophilic fungi on human hair. 2. Degradation of human hair by Malbranchea 3. C. queenslandicum 4. Degradation of chicken feather by C. indicum 5. Feather degradation by C. tropicum 6. Degradation of human hair by Humicola grasiea 7. Growth of Chrysosporium pannicola on chicken feather 8 . Colonization of $A$. strictum on chicken feather 9. Colonization of $P$. variotii on feather rachis. 
species developed hype that grew only on either side and bore reproductive structures at their terminal position (Fig. 2). Growth was observed to begin at the rachis and to extend towards the whole feather, which may lead to erosion. Chrysosporium queenslandicum caused uniform erosion in feather (Fig. 3). C. indicum caused complete degradation of the feather, including rachis (Fig. 4). C. tropicum with thin hyphae, produced short, narrow perforating organs (Fig. 5). However, the simple growth of a fungus on keratin residues, often visible with naked eyes was not a sufficient demonstration of keratinolytic activity. Humicola grisea by hyphal penetration caused longitudinal splitting of hair (Fig. 6). It was observed that a tuft of fungal mycelium attacked feather rachis so that lifting may occur. The medulla appeared to be filled with masses of conidia before wide penetrating organs attacked the cortex (Fig. 7). Acremonium sritctum caused digestion as a result of massive growth (Fig. 8). The conidia of Paecilomyces variotii (Fig. 9) were developed at the end of the feather rachis. Fusarium oxysporum developed head shaped, longitudinal and broad perforators were observed (Fig. 10). C. tropicum formed perforating the organs on human hair (Fig. 11). Degradation activity of Aspergillus wentii was observed on human hair (Fig. 12). There was continuing damage of hair from the outside inwards by hyphae, which lifted up the cuticle and then digested the scales, starting from the inner side. It is assumed that after surface erosion by the fungus, it will be able to penetrate under the cuticle and in between the layers of cuticular cells. Feather degradation by Paeciliomyces sp. was observed on feather (Fig. 13). According to Griffin (1960) and De Vries (1962) some fungi that only colonize keratinous baits are not able to attack keratin, but simply use the products of its partial demolition by other fungi, the protoplasmic residues of the keratinic matrices or substances naturally present on their surface. Deacon (1980) suggested that the more massive organs are characteristics of keratinolytic fungi, while the non- keratinolytic fungi produced the narrow, boring hyphae. Safranek and Goos (1982) defined that growth of fungi on hair segments without perforating organs may be due to their utilization of non-keratinous substrate present in the hair. Pathogenic activities of Paecilomyces variotii was also reported by Naidu and Singh (1992). Keratinolysis has been represented by two forms of attack i,e. surface erosion and radial penetration (Ali-Shtayeh, 2000).

Keratinase activity has been reported in Chaetomium globosum by Safranek and Goos (1982) and Scott and Untereiner, (2004). It is conceivable that moderately and negligible keratinolytic strains exist within one species. In Scopulariopsis brevicaulis, for example, some authors described keratinolytic ability (Benedicto 1973) while others could not find it (Kunert 1989). Fusarium and Acremonium species were seen to have invaded the full thickness of the epidermis with some degree of invasion of the dermal layer (Richardson and Edward, 2000). This is for the first time, as non dermatophytic ones showed broad perforators. The disintegration of hair was caused by dermatophyte enzymatic digestion (Richardson and Edward, 2000). However, some non dermatophytes have also been implicated as keratin digestor (Malviya et al., 1992, Kaul and Sumbali 1999). Keratin degradation capability was described by Kumar et al. (2020).

FTIR analysis: In order to understand the structure of undegraded and microbial degraded feather FTIR spectra was used. This analysis confirmed the purpose of $\mathrm{COOH}$ and $\mathrm{NH}_{2}$ group. The significant change was seen in the amide region of a fungal degraded feather. After a comparison of samples were found that the characteristic peaks are similar to each other and comparable with another study for feathers (Ma et al., 2016). Have band region between $3500-3200 \mathrm{~cm}^{-1}$ was attributed to starching vibration of $-\mathrm{O}-\mathrm{H}$ - and $-\mathrm{N}$ $\mathrm{H}$ amide band (Pavia et al., 2008) appeared in the range between $3000-2800$ were related to symmetrical $-\mathrm{CH}_{3}$ stretching vibration. The strong band was

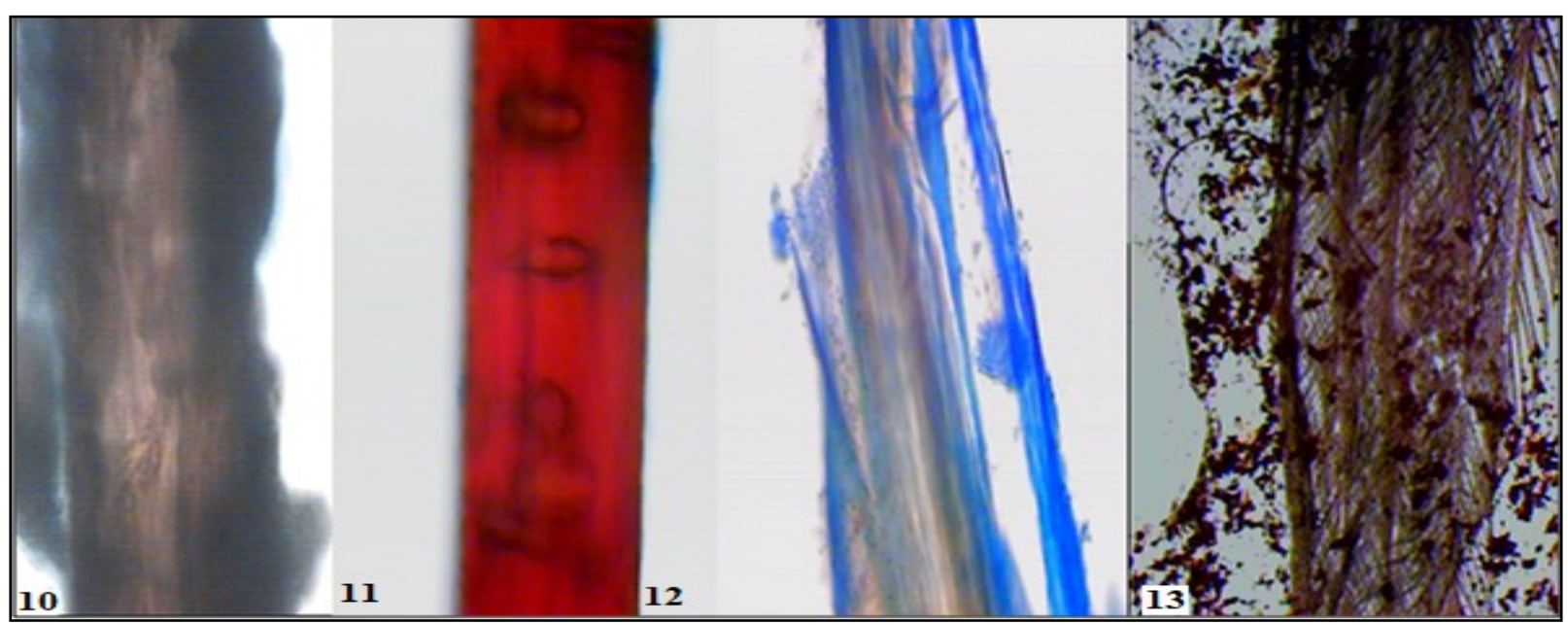

Figs. 10-13: 10. Colonization of human hair by F. oxysporum. 11. Formation of perforating organs by C. tropicum. 12. Degradation of human hair by A. wentii 13. Chicken feather degradation by Paeciliomyces sp. 
attributed to -CO- stretching (amide I) which occurred in the range of $1700-1600 \mathrm{~cm}^{-1}$ (Mohanty et. al., 2005). The band (amide II) was in the range of $1580-1480 \mathrm{~cm}$ ${ }^{-1}$ is for $-\mathrm{N}-\mathrm{H}$ banding and $\mathrm{C}-\mathrm{H}$ stretching for wool and feathers (Eslahi et al., 2013). The weak band between $1300-1220 \mathrm{~cm}^{-1}$ was associated with amide III, which was derived from $\mathrm{C}-\mathrm{N}$ stretching $\mathrm{C}-\mathrm{O}-$ bond band and C-C stretching (Vasconcelos et al., 2008). In the sulphoxide region at $1073 \mathrm{~cm}^{-1}$ the band corresponding to $\mathrm{S}$ -O was observed for undegraded feathers (Fig. 14). The band posed with low intensity and was poorly visible, while in degraded feather, the intensity of the band

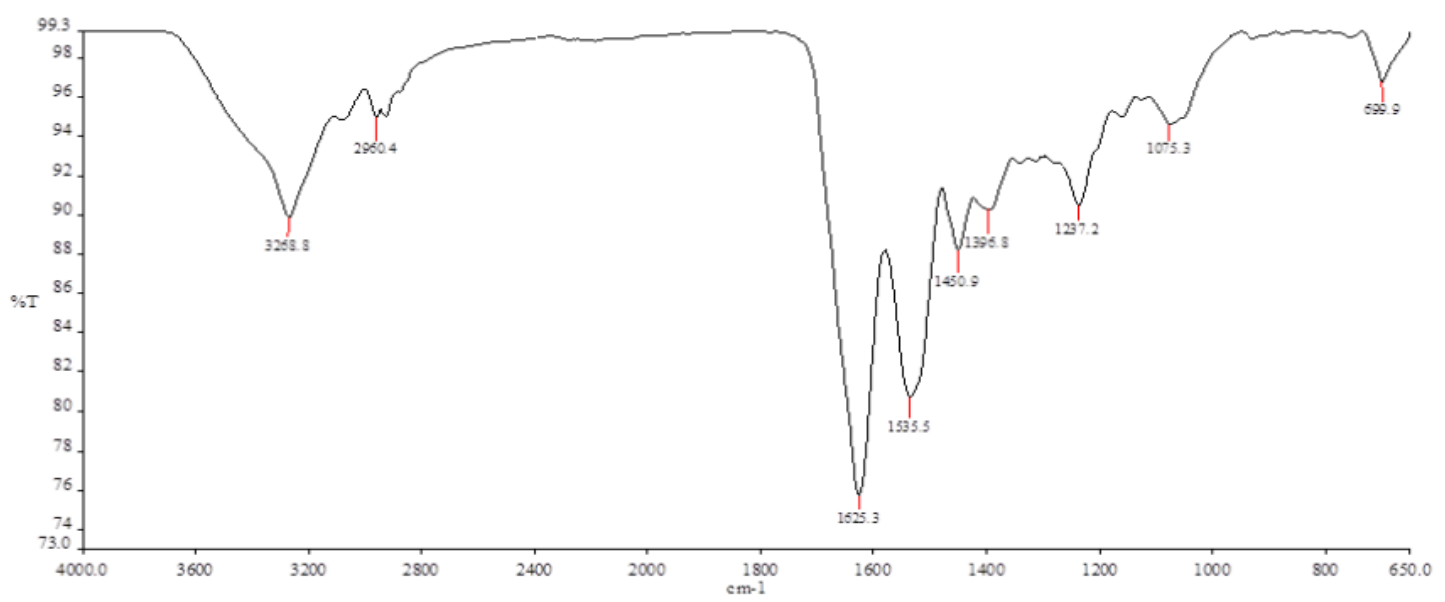

Fig. 14: FTIR spectra of no degraded chicken feather.

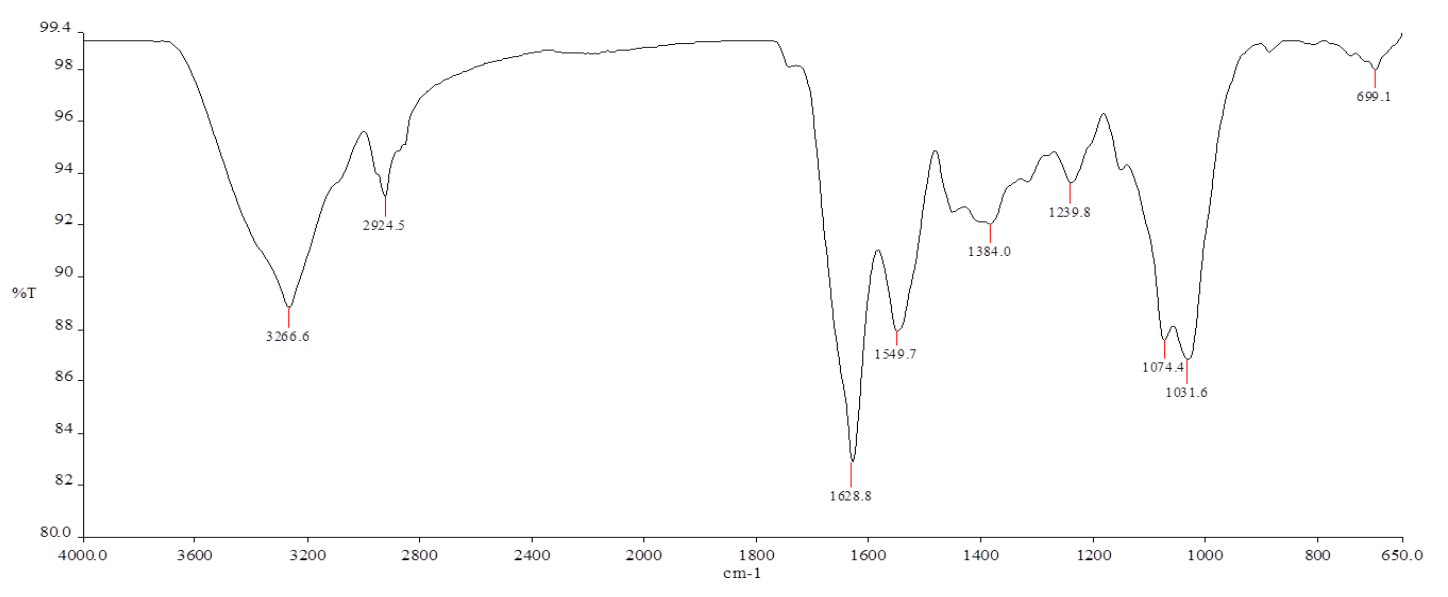

Fig. 15: FTIR spectra of C. tropicum degraded feather of chicken.

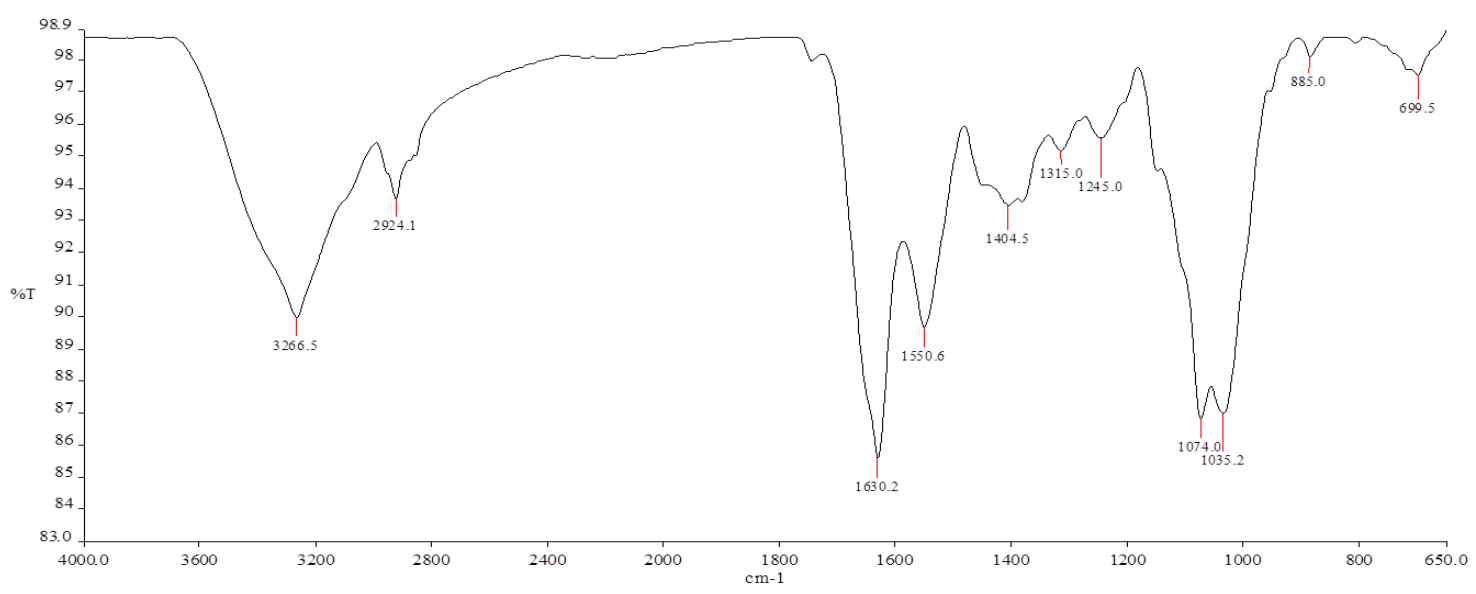

Fig. 16: FTIR spectra of C. indicum degraded chicken feather. 
was high in case of $C$. indicum and $C$. tropicum the band between $750-600 \mathrm{~cm}^{-1}$ was related to $-\mathrm{N}-\mathrm{H}$ out of plane banding (Fig. $15 \& 16$ ). In the case of human hair, the amide I, II, III at $1635 \mathrm{~cm}^{-1}, 1535 \mathrm{~cm}^{-1}$ and $1235 \mathrm{~cm}^{-1}$ respectively was in accordance with other reports for horsehair (Callin et al., 2017). The band was observed for undegraded hair (Fig. 17). In the sulphoxide region at $1029-1034 \mathrm{~cm}^{-1}$, the band corresponding to $\mathrm{S}-\mathrm{O}$ was observed. The band posed with high intensity and was clearly visible in C. indicum (Fig. 18) while the intensity of the band was low in case of C. tropicum (Fig. 19).

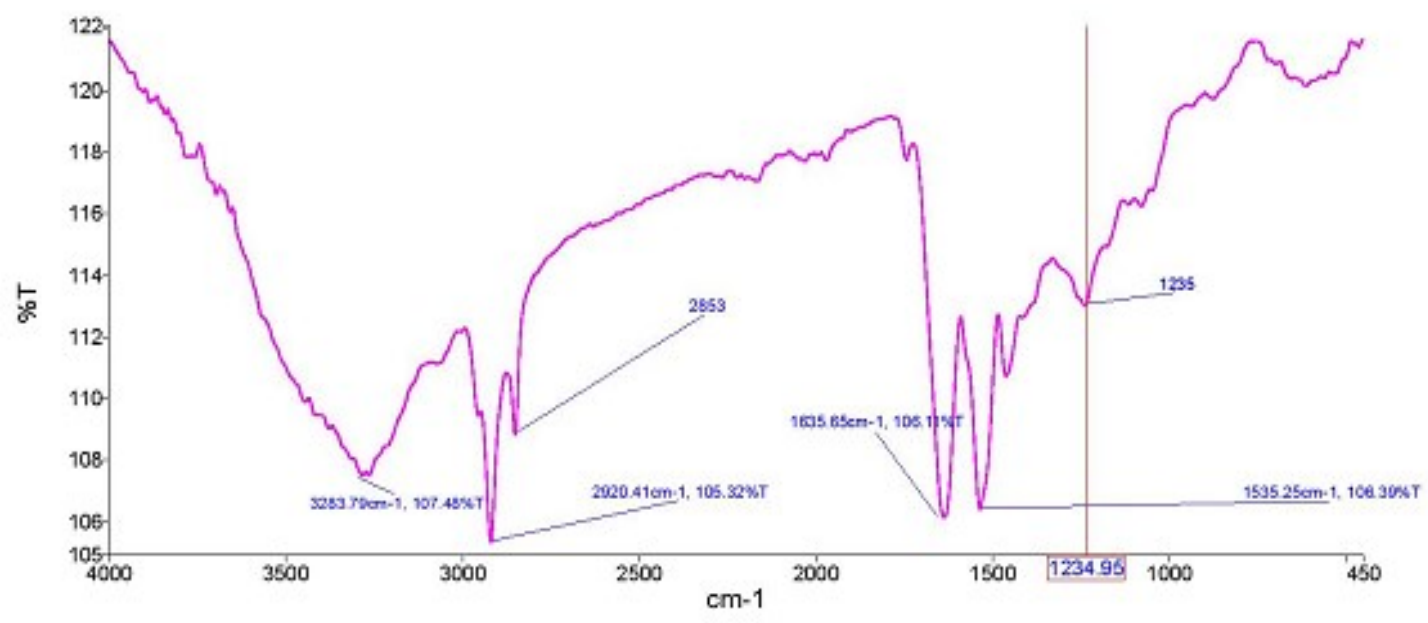

Fig.17: FTIR spectra of undegraded human hair.

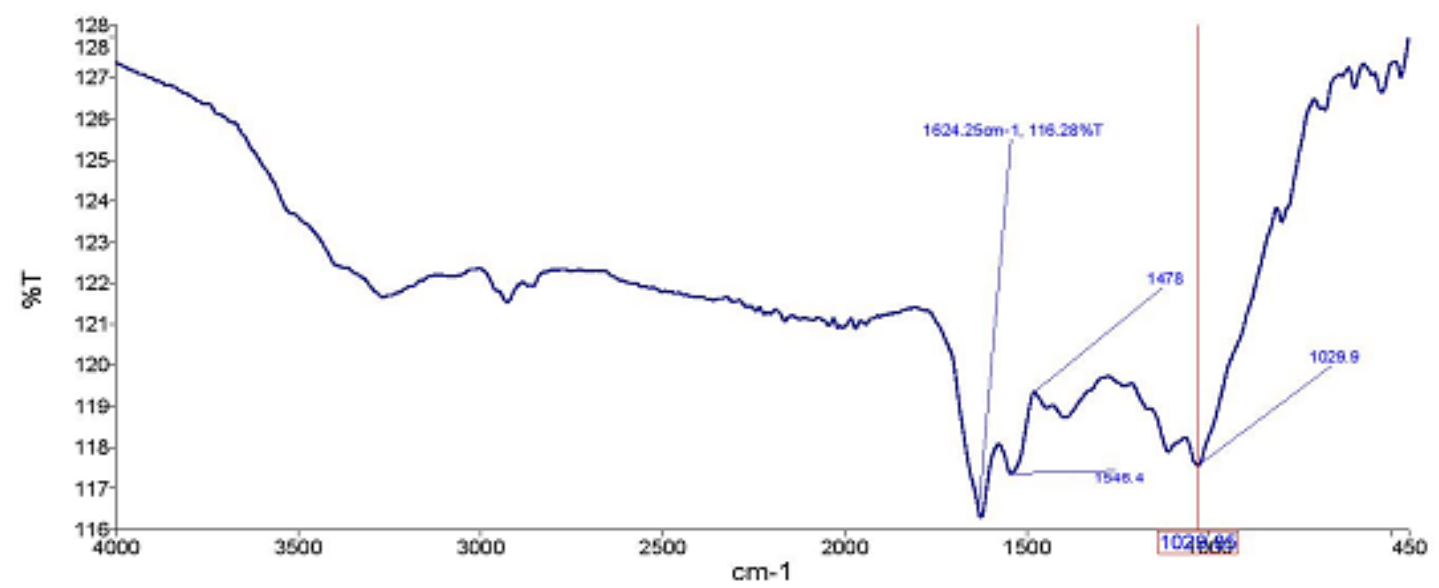

Fig. 18: FTIR spectra of C. indicum degraded human hair.

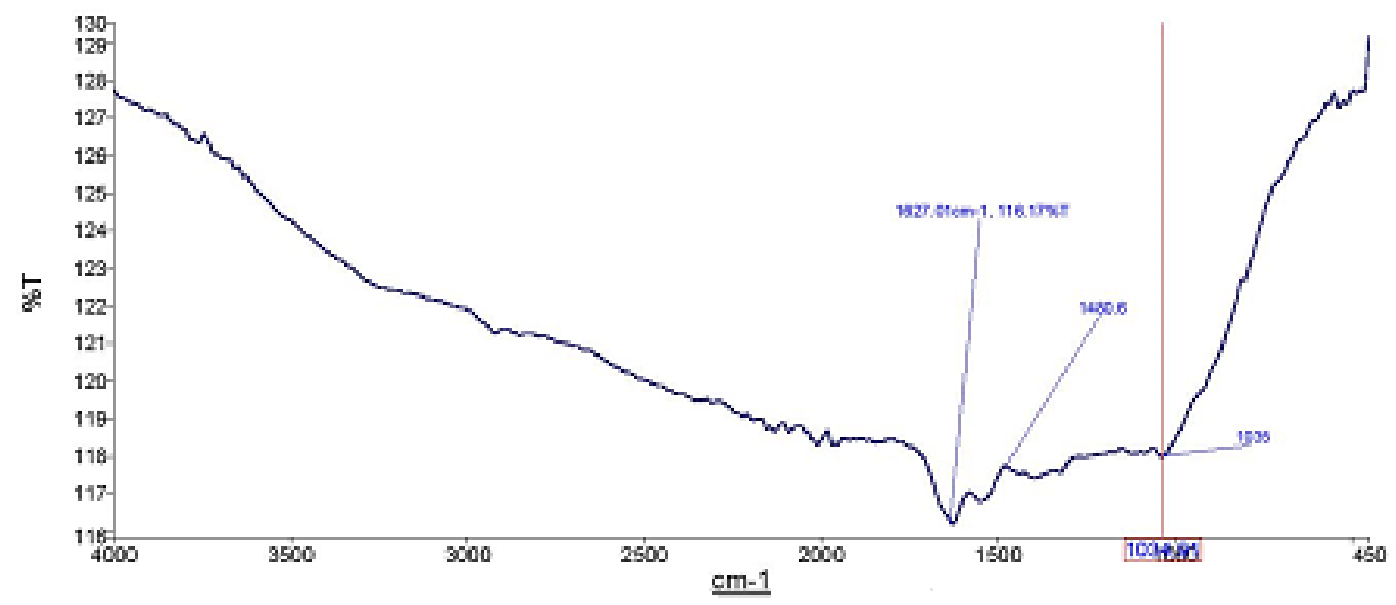

Fig. 19: FTIR spectra of C. tropicum degraded human hair. 


\section{Conclusion}

The present study indicated partial to complete keratin deterioration by $A$. strictum, $A$. wentii, C. indicum, $C$. pannicola, C. tropicum, C. queenslandicum, F. oxysporum, Humicola grasiea, Malbranchea, P. variotii, Paeciliomyces sp. on feather and human hair. FTIR analysis of degraded feather and hair by $C$. indicum and $C$. tropicum confirmed the presence of amino and sulphoxide group. During the degradation process, S$S$ bond was broken by $C$. tropicum and $C$. indicum due to proteolytic enzymes. This study suggests that these selected nondermatophytic fungi from soil can be used as decomposer of keratinous waste management and convert them into valuable byproducts.

\section{ACKNOWLEDGEMENTS}

Authors are thankful to Dr. R.K. S. Kushwaha, Former Professor \& Emeritus Fellow UGC, Department of Botany, Christ Church College, Kanpur for valuable suggestion during manuscript preparation and identification of fungi.

\section{Conflict of interests}

The authors declare that they have no conflict of interests.

\section{REFERENCES}

1. Ali-Shtayeh, M.S., Rana and M.F., Jamous. (2000). Keratinophilic fungi and related dermatophytes in polluted soil and water habitats. In: Kushwaha, RKS \& Guarro, J, eds. Biology of dermatophytes and other keratinophilic fungi. Spain: RIAM. 51-59.

2. Bairwa, S. and Sharma, M. (2020). Isolation and purification of keratinophilic fungi and dermatophytic fungi from some public places of Jaipur city India. International Journal of Pharma and Bioscience, doi 10.22376/ ijpbs.2020.11.1.b6-10.

3. Benedek, T. (1962). Fragmenta mycologia I. Some historical remarks on the development of "hair baiting" of TomaKarling-Vanbreuseghem (The To-Ka-Va hair baiting method). Mycopathol Mycol Appl., 16: 104-106.

4. Benedicto, T. (1973). Contibution a letude du Scopulariopsis brevicaulis Bainier. Recherche de conditions optimales de croissance, activite proteolytique et keratinolytique in vitro. These de Doctorat, Faculte des Sciences, Toulouse.

5. Bohacz, J., Kornillowicz-Kowalska, T., Kitowski, I., Ciesielska, A. (2020). Degradation of chicken feathers by Aphanoascus keratinophillus and Chyrsosporium tropicum strains from pellets of predatory birds and its practical aspect. International Biodeterioration \& Biodegradation, 151(2020): 104968.

6. Callin, M., Constantinescu-Alexandrescu, D., Alexandrescu, E., Raut, I., et al., (2017). Degradation of keratin substrate by keratinolytic fungi. Electronic Journal of Biotechnology. 28: 101-112.

7. Caretta, G. and Piontelli, E. (2004). Keratinophlous fungi from Antarctic terrestrial habitats. In Kushwaha RKS (eds.) Fungi in human and animal health. Scientific Publishers Jodhpur India, 29-38.

8. Deshmukh, S.K. (1999). Keratinophic fungi isolated from soils of Mumbai, India. Mycopathologia, 146: 115-116.
9. Deshmukh, S.K. and Verekar, S.A. (2006). The occurrence of dermatophytes and other keratinophilic fungi from the soils of Himachal Pradesh (India). Czech Mycol., 58(12): 117-124.

10.Deshmukh, S.K., Verekar, S.A. and Shrivastav, A. (2010). The occurrence of keratinophilic fungi in selected soils of Ladakh (India). Natural Science, 2(11): 1247-1252.

11.De Vries, G.A. (1962). Keratinophilic fungi and their action. Antonie van Leeuwenhoek. 28: 121-133.

12.Deacon, J.W. (1980). Introduction to Modern Mycology. Halsted Press, New York. 170-172.

13.Eslahi, N., Dadashian, F. and Nejad, N.H. (2013). An investigation on keratin extraction from wool and feather waste by enzymatic hydrolysis. Prep Biochem Biotechnol, 43:624-648.

14.Filipello, M.V. (1986). Keratinolytic and keratinophilic fungi of children's sandpits in the city of Turin. Mycopathologia, 94:163-172.

15.Griffin, D.M. (1960). Fungal colonization of sterile hair in contact with soil. Trans Brit Mycol. Soc., 43:583-596.

16. Hubalek, Z. (2000). Keratinophilic fungi associated with free living mammals and birds. In: In. Kushwaha RKS and Guarro J (eds.) Biology of dermatphytes and other keratinophilic fungi, RIAM Spain. 90-103.

17.Kane, J., Summerbell, R., Sigler, L., Krajden, S. and Land, G. (1997). Laboratory handbook of Dermatophytes. Belmont, Ca (USA), Star Publishers. 213-231.

18.Kaul, S. and Sumbali, G. (1999). Production of extracellular keratinase by keratinophilic fungal species inhabiting feathers of living poultry birds (Gallus domesticus): a comparison. Mycopathologia, 146: 19-24.

19.Kumar, J. and Kushwaha, R.K.S. (2014). Screening of fungi efficient in feather degradation and keratinase production. Archives of Applied Science Research. 6(1), 7378.

20.Kumar, J., Kumar, P., Kushwaha, R.K.S. (2015). Feather waste degradation by keratinophilic fungi: An alternative source for protein and amino acid. Adv. Appl. Sci. Res, 6 (11): 160-164.

21.Kumari, M. and Kumar, J. (2020). Chicken feather waste degradation by Alternaria tenuissima and its application on plant growth. Journal of Applied and Natural Sciences, 12 (3): 411-414.

22.Kumar, J., Kumar, P. and Kushwaha, R.K.S. (2020). Recycling of chicken feather protein into compost by Chrysosporium indicum JK14 and their effect on the growth promotion of Zea mays. Plant Cell Biotechnology and Molecular Biology, 21(37\&38): 75-80.

23.Kunert, J. (1972). The digestion of human hair by the dermatophyte, Microsporum gypseum in a submerged culture. Mykosen, 15: 59-71.

24.Kunert, J. (1989). Growth of keratinolytic fungi and non keratinolytic fungi on human hairs. A physiological study. Acta Universit Olomouc Facul Medic, 122: 25-38.

25.Kwon-Chung, K.J. and Bennett, J.W. (1992). Medical Mycology. Philadelphia, Lea and Febiger, 105-161.

26.Ma, B., Qiao, X., Hou, X. and Yang, Y. (2016). Pure keratin membrane and fibers from chicken feather. Int. J. Biol. Macromolecles, 89:614-621.

27.Malviya, H., Rajak, R.C. and Hasija, S.K. (1992). Purification and partial characterization of two extracellular keratinases of Scopulariopsis brevicaulis. Mycopathologia, 119: 161-165.

28.Mohanty, A.K., Misra, M. and Drzal, L.T. (2005). Natural Fibres, Biopolymers and Bio Compsites, Ist Edition, CRC 
press, pages 896 .

29.Nigam, N. and Kushwaha, R.K.S. (1990). Biodeterioration of human hair. J Ind. Bot. Soc., 69: 1-2.

30.Nigam, N. and Kushwaha, R.K.S. (1992). Biodegradation of wool by Chrysosporium keratinophilum acting singly or in combination with other fungi. Trans Japan Mycol Soc., 33: $481-486$.

31.Naidu, J. and Singh, S.M. (1992). Hyalohyphomycoses caused by Paecilomyces variotii: a case report, animal pathogenecity and in vitro sensitivity. Antonie van Leeuwenhoek, 62: 225-230.

32.Pasupuleti, V.K., Holmes, C. and Demain, A.L. (2010). Applications of protein hydrolysates in biotechnology. Springer Netherlands, pp. 1-9.

33.Pavia, D.L., Lampman, G.M., Kriz, G.S. and Vyvyan, J.A. (2008). Introduction to spectroscopy, fifth edition, Cengage learning, USA, pages 786 .

34.Peng, Z., Mao, X., Zhang, J., Du, G. and Chen, J. (2019). Effective biodegradation of chicken feather waste by cocultivation of keratinase producing strains. Microb. Cell Fact. 18:84. https://doi.org/10.1186/s12934-019-1134-9

35.Ramesh, V.M. and Hilda, A. (1999). Incidence of keratinophilic fungi in soil of primary schools and public parks of Madras City, India. Mycopathologia, 143: 139-145.
36.Richardson, M. and Edward, M. (2000). Model systems for the study of dermatophyte and non-dermatophyte invasion of human keratin. In: Kushwaha, RKS \& Guarro, J. (eds) Biology of dermatophytes and other keratinophilic fungi. RIAM Spain, 115-121.

37.Safranek, W.W. and Goos, R.D. (1982). Degradation of wool by saprophytic fungi. Can J Microbiol., 28: 138-140.

38.Sahoo, D.K., Das A., Thatoi H., Mondal K.C. and Mohapatra P.K.D. (2012). Keratinase production and biodegradation of whole chicken feather keratin by a newly isolated bacterium under submerged fermentation. Appl. Biochem. Biotechnol., 167:1040-1051.

39.Sharma, R. (2016). Some keratinophilic fungi new to India. J. Mycopathol. Res., 54(1): 35-39

40.Scott, J.A. and Untereiner, W.A. (2004). Determination of keratin degradation by fungi using keratin azure. Med. Mycol., 42: 239-246.

41.Vasconcelos, A., Fredid, G. and Cavaco-Paulo, A. (2008). Biodegradable materials based on silk fibroin and keratin. Biomacromolecules, 1299-1305.

42.Wawrzkiewicz, K., Wolski, T. and Lobarzewski, J. (1991). Screening of the keratinolytic activity of dermatophytes in vitro. Mycopathologia, 114: 1-8. 